\title{
IMPACT OF THE METHOD OF RAIL TRACK ROUTING ON THE THERMAL REGIME OF SUBGRADE STRUCTURE - NUMERICAL MODELING OF NON-TRAFFIC LOAD
}

\author{
LIBOR IŽVOLT, PETER DOBEŠ \& STANISLAV HODÁS \\ Department of Railway Engineering and Track Management, Faculty of Civil Engineering, \\ University of Žilina, Slovakia
}

\begin{abstract}
The article uses numerical modelling to verify the impact of non-traffic load (water and frost) on subgrade structure freezing of railway tracks with different routing (embankment and cut). The introduction characterizes two actual railway track models in the campus of the University of Žilina, named experimental stand DRETM - Department of Railway Engineering and Track Management (two measuring profiles were considered here: second measuring profile - embankment, third measuring profile - cut). The second part of the article brings the results of numerical modelling of non-traffic load impact on subgrade structure freezing in two respective profiles. Here, the course of the winter period 2016/2017 for Zilina and the climatic conditions of the winter period 2004/2005 measured for Poprad were applied (the values of the air frost index achieved in Poprad were approximately identical to or higher than the values in Žilina). The conclusion includes a comparison of the individual methods of rail track routing, a summary of achieved results of numerical modelling of subgrade structure freezing and sufficiency assessment of subgrade surface protection from the adverse effects of frost.
\end{abstract}

Keywords: railway track, subgrade structure, subgrade structure freezing, protective layer, numerical modelling

\section{INTRODUCTION}

Applying the Canadian software SoilVision [1], it is generally possible to conduct the numerical modelling of the thermal regime of railway track for any winter period. In other words, it is possible to identify the maximum freezing depth of railway structure in this way. To achieve relevant results, it is necessary to determine the input data (values of temperature and humidity of not only materials of individual structural layers but also of railway track substructure and thermal-technical properties of materials and climatic characteristics of a given area). To monitor the thermal regime of the subgrade structure at the Department of Railway Engineering and Track Management, an experimental stand DRETM I was constructed. However, some deficiencies of this experimental stand were soon revealed, primarily related to the Soilvision software (inability to identify humidity and its variation in the individual structural parts during the year). The Faculty of Civil Engineering also moved to a new, modern campus. Due to these reasons, in 2013, a new experimental stand DRETM II, able to provide the requested data, had to be built.

This stand was a railway track model at the scale of $1: 1$. The original plan was to build in two types of railway subgrade - two measuring profiles - the first measuring profile was an embankment without the protective layer and the second measuring profile was an embankment with the protective layer of the structural thickness of $450 \mathrm{~mm}$. The first results of experimental monitoring of the thermal regime of railway track (subgrade structure), as well as numerical modelling, showed a very good agreement. Thus, a trouble-free subsequent comparison of results was feasible. The only tested structure was the standard subgrade structure that was a part of the embankment; according to Ref. [2], it was the subgrade structure no. 2. In order to gain and deepen knowledge on the course of the thermal regime and the 
freezing depth of railway structure also for other boundary conditions, another major decision was taken. In the winter period 2016/2017, monitoring of the impact of the non-traffic load at the experimental stand DRETM I was finished and there is a plan to gradually extend the experimental stand DRETM II to other test fields. The aim is to identify the impact of not only thermal insulation materials built in the subgrade structure, but also the impact of the shape of railway substructure (embankment and cut) or the method of railway track routing on subgrade structure freezing. In 2016, two other subgrade structures were built - two measuring profiles, i.e. the third measuring profile with an inbuilt protective layer of crushed aggregate fr. 0/31.5 $\mathrm{mm}$, of the structural thickness $450 \mathrm{~mm}$ and the fourth measuring profile with a protective layer of a thermal insulation material Liapor of the structural thickness $150 \mathrm{~mm}$. Both subgrade structures - measuring profiles - are railway structures routed in a cut. In 2017, the experimental stand was extended in latest subgrade structures - the fifth measuring profile with the thermal insulation material Styrodur, $50 \mathrm{~mm}$ thick, and a layer of crushed aggregate, $150 \mathrm{~mm}$ thick. Moreover, the sixth measuring profile with a different thermal insulation layer - cement-bound Liapor (Liapor concrete) was built in. Both subgrade structures - measuring profiles - are rail structures routed in an embankment and basically can be seen as upgraded first and second measuring profiles of the original experimental stand DRETM II.

After completion of this experimental stand construction and the end of measurements at the experimental stand DRETM I, renaming was necessary for the purpose of simpler identification of measurement results. The extended experimental stand DRETM II is at present referred to as experimental stand DRETM. The cross-sections of subgrade structures (measuring profiles), which had been studied in relation to the impact of the method of rail track routing on the thermal regime of subgrade structure, and were a part of the experimental stand DRETM II, remained unchanged. They were thus included in the experimental stand DRETM.

The article only focuses on the impact of the shape of railway substructure - method of rail track routing - on railway (subgrade structure) freezing. Figure 1 demonstrates a crosssection of the second measuring profile (embankment) and Fig. 2 a cross-section of the third measuring profile (cut).

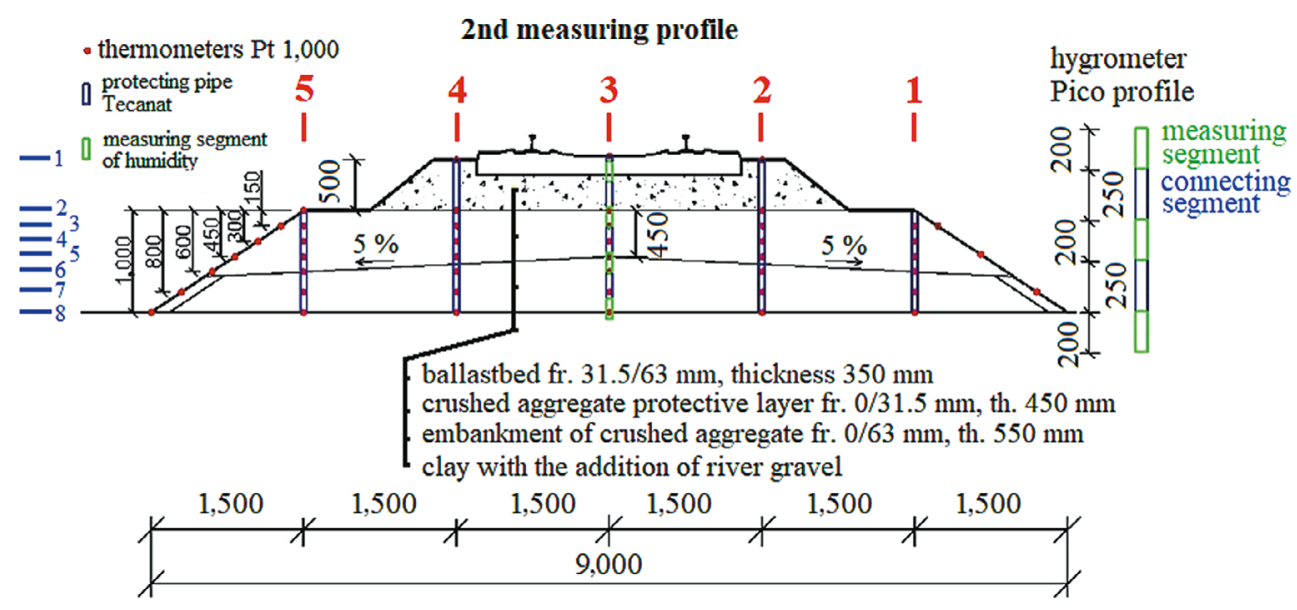

Figure 1: Experimental stand DRETM - second measuring profile. 


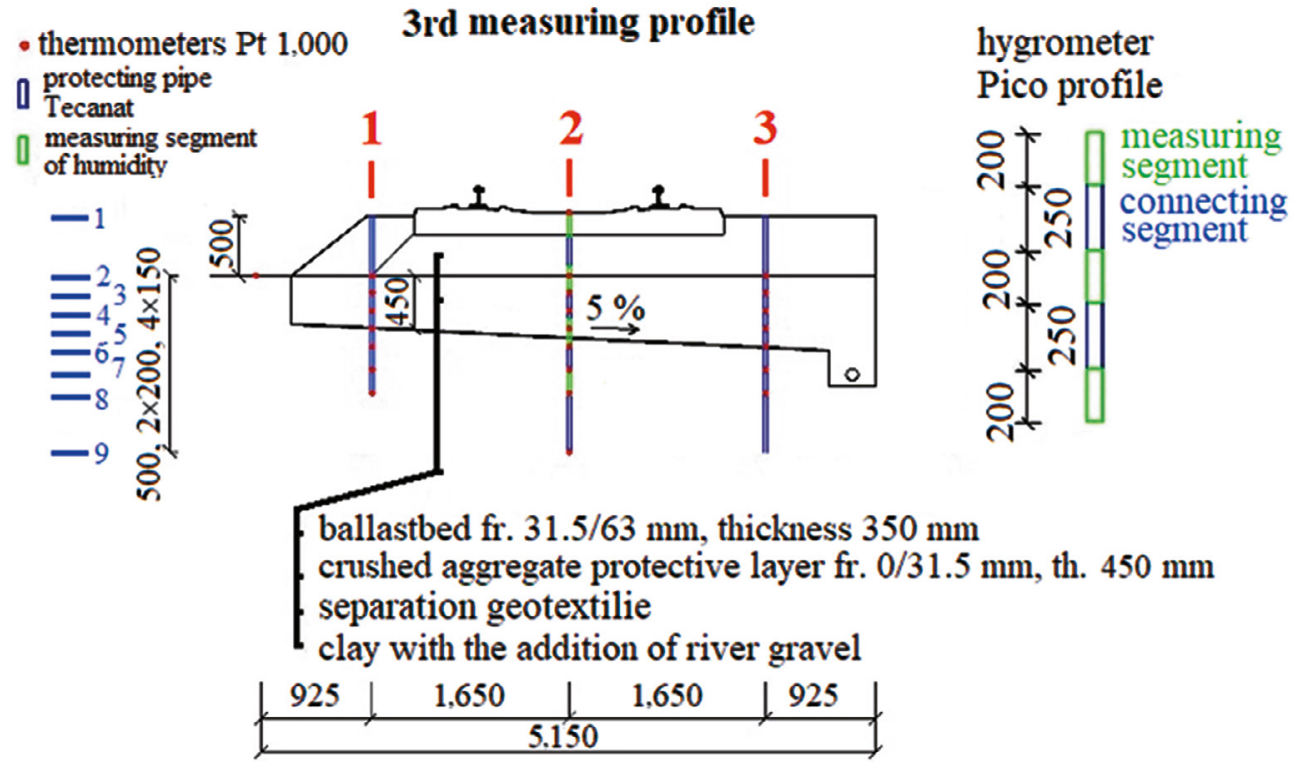

Figure 2: Experimental stand DRETM - third measuring profile.

Both the measuring profiles include a protective crushed aggregate layer, fr. 0/31.5 mm, $450 \mathrm{~mm}$ thick, and a ballast bed, fr. $31.5 / 63 \mathrm{~mm}$. The thickness of the protective layer was designed for the climatic conditions in Žilina, by the methodology stated in Ref. [2]. Clay with the addition of river gravel composes the subgrade. In addition to this, the second measuring profile includes a structural layer that forms an embankment of crushed aggregate, fr. $0 / 63 \mathrm{~mm}$.

Until now (the time of writing this paper), for the second measuring profile four winter periods and for the third measuring profile only one winter period (2016/2017) have been recorded. In this winter period, the recorded value of the frost index was $I_{F}=-284^{\circ} \mathrm{C} \cdot$ day, which is approximately $60 \%$ of the design value of the frost index for the area of Žilina $\left(I_{F d}=\right.$ $470^{\circ} \mathrm{C}$-day). For numerical modelling and comparison of various railway track routing methods, with respect to the subgrade structure freezing, the winter period 2004/2005 in Poprad was used. This was caused by several reasons, specifically, only one winter period was available, and in that winter period, the value of the frost index close to the design value was not achieved. The value of the frost index in Poprad $I_{F}=-464^{\circ} \mathrm{C} \cdot$ day is close to the design value of the frost index in the area of Žilina. The climatic characteristics of the respective winter period for Poprad were obtained from the Slovak Hydrometeorological Institute. The course of the mean daily temperature values of as well as the achieved value of the frost index can be seen in Fig. 3.

In the further part of the article, attention is paid to the numerical modelling of winter period as shown in Fig. 3 and comparison of achieved results in both railway track models that differ in the method of rail track routing (embankment and cut). 


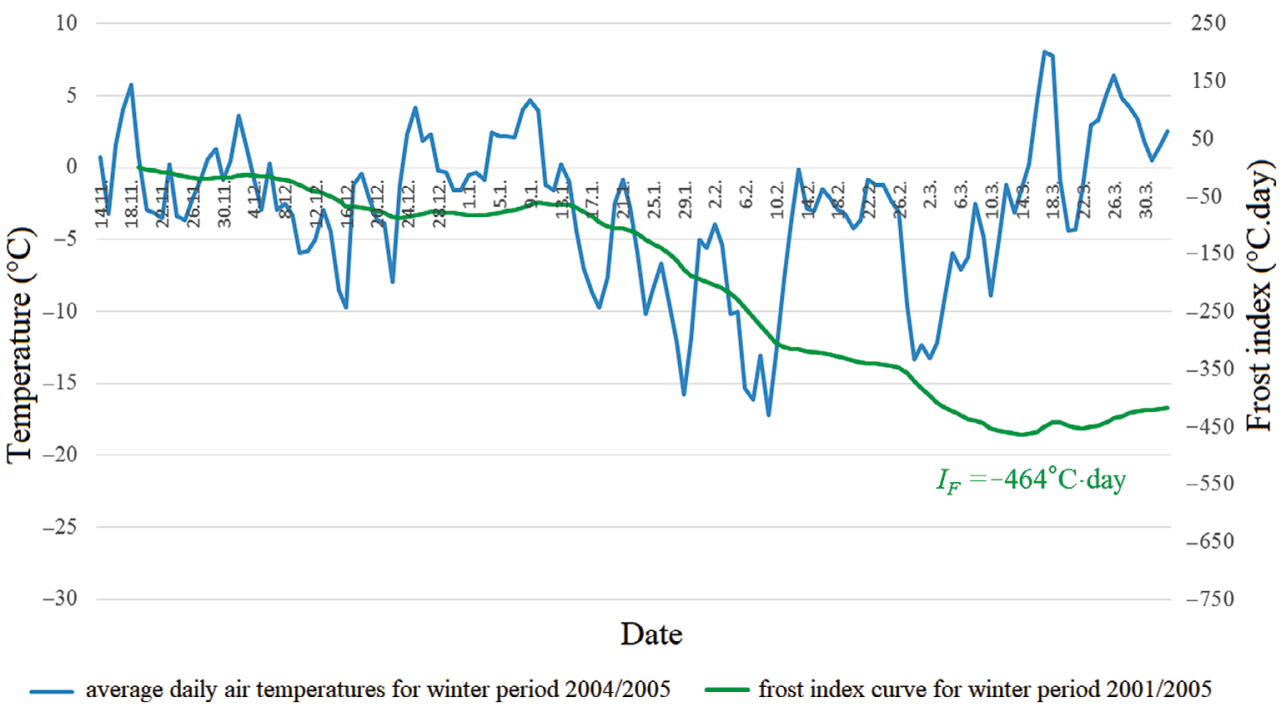

Figure 3: Course of daily mean air temperatures and frost index in winter period 2004/2005 in Poprad.

\section{NUMERICAL MODELLING OF FREEZING OF MONITORED RAILWAY TRACK STRUCTURES}

The subgrade structure freezing and its subsequent volume changes in winter and spring periods are among the primary causes of changes of track layout and geometry. These changes greatly affect the driving comfort and safety of railway vehicles on a track. The weakest link in the subgrade structure is the subgrade surface. Therefore, the structural layer composition must be designed and implemented with the goal to protect it wholly or partially (on tracks for slower speeds and operational load) from the effects of climatic factors (water and frost) [3].

For own numerical modelling, it was necessary to create a railway track model. To meet this purpose, the geometric dimensions and material composition of the experimental stand DRETM were applied (Fig. 4 - a model of the second measuring profile and Fig. 5 - a model of the third measuring profile).

The characteristics of the model structural layers, gained by experimental measurements at the experimental stand DRETM, or laboratory measurements (thermal-technical parameters), are shown in Table 1.

The snow cover could not be considered in the numerical modelling due to absent information on its presence or thickness. Therefore, the conversion of the mean daily air temperature to a surface mean daily temperature (on ballast bed surface) was conducted using $n_{f}$ factor. The value of the $n_{f}$ factor was gained by a comparison of given parameters. For the purposes of numerical modelling of the railway track freezing process of the winter period 2004/2005, the value 0.60 was considered.

As stated in the Introduction, the climatic characteristics of the winter period 2004/2005, recorded in Poprad, were considered for numerical modelling of subgrade structure freezing 


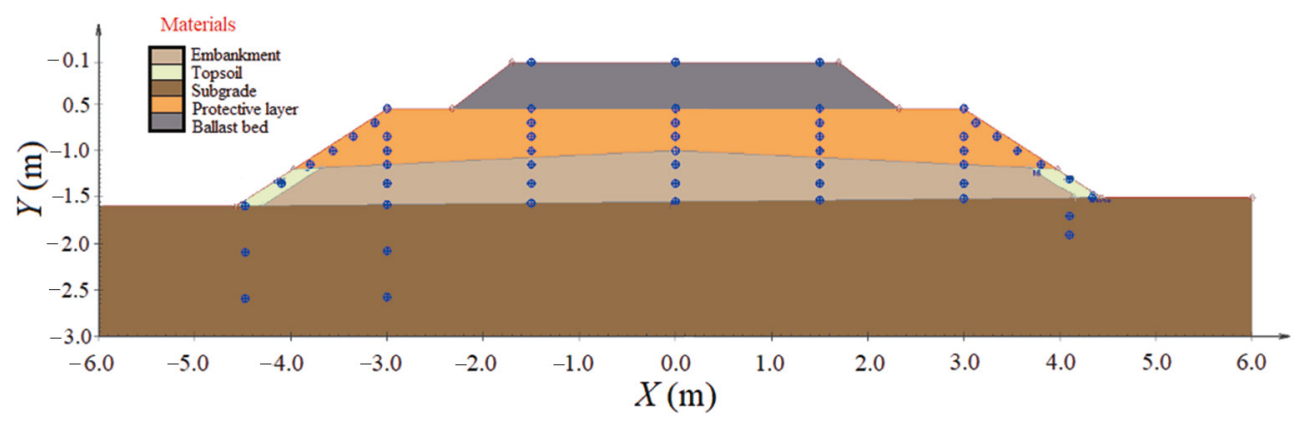

Figure 4: Model of the experimental stand DRETM - second measuring profile [4].

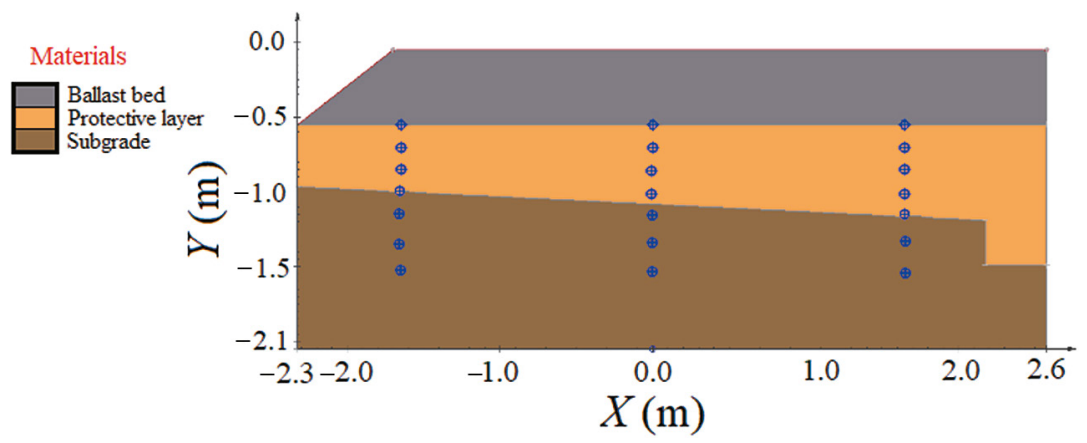

Figure 5: Model of the experimental stand DRETM - third measuring profile.

Table 1: Input parameters for numerical modelling [5].

\begin{tabular}{|c|c|c|c|c|c|}
\hline $\begin{array}{l}\text { Structural layer/ } \\
\text { characteristics }\end{array}$ & Ballast bed & $\begin{array}{l}\text { Protective } \\
\text { layer }\end{array}$ & Embankment & Subgrade & Humus \\
\hline Layer temperature $\left({ }^{\circ} \mathrm{C}\right)$ & 8 & 8 & 10 & $11(9)$ & 8 \\
\hline Layer humidity $w_{m}(\%)$ & 1 & $6\left(3^{*}\right)$ & 5 & 16 & 20 \\
\hline $\begin{array}{l}\text { Volumetric capacity in a dry } \\
\text { state } \rho_{0}\left(\mathrm{~kg} \cdot \mathrm{m}^{-3}\right)\end{array}$ & 1,908 & 1,928 & 2,090 & 1,646 & 1,320 \\
\hline $\begin{array}{l}\text { Volumetric heat capacity in } \\
\text { a dry state } C_{0}\left(\mathrm{~J} \cdot \mathrm{kg}^{-1} \cdot \mathrm{K}^{-1}\right)\end{array}$ & 980 & 1,088 & 1,050 & 1,495 & -*** \\
\hline $\begin{array}{l}\text { Thermal conductivity } \\
\text { coefficient } \\
\lambda\left(\mathrm{W} \cdot \mathrm{m}^{-1} \cdot \mathrm{K}^{-1}\right)\end{array}$ & 0.67 & $\begin{array}{l}1.93 \\
(1.00 *)\end{array}$ & 1.42 & $\begin{array}{l}0.81 \\
(0.97 * *)\end{array}$ & $\begin{array}{l}1.12 \\
\left(1.35^{* *}\right)\end{array}$ \\
\hline
\end{tabular}

*Change of an input parameter of a cut model.

**Value of frozen material.

$* * *$ Value entered depending on a volumetric heat capacity. 
due to the reached value of the frost index $\left(I_{F}=-464^{\circ} \mathrm{C} \cdot\right.$ day $)$. This value is approximately identical to the design value of the frost index $\left(I_{F d}=-470^{\circ} \mathrm{C} \cdot\right.$ day $)$, which was considered in the design of the structural layer parameters of the experimental stand DRETM. The respective winter period can be characterized by one long frost period that lasted 123 days (19 November 2004 to 22 March 2005). This period was interrupted by several shorter (lasting fewer than 4 days) and three longer (lasting minimally 4 days) warm periods. Although the frost period of the winter period 2004/2005 starts on 19 November 2004, the beginning of the period in the model was determined on 14 November 2004 (TIME =1), due to the occurrence of isolated negative average daily temperature a day after. The end of the period was determined on 1 April 2005 (TIME = 139), which is 10 days after the end of the frost period of the winter period 2004/2005. The period for the purposes of numerical modelling in the model, as shown in Figs 4 and 5, thus lasts 139 days. The most interesting days are TIME = 131 (maximum freezing value for the embankment, $D_{F}=0.97 \mathrm{~m}$ ) and TIME $=137$ (maximum freezing value for the cut, $D_{F}=0.97 \mathrm{~m}$ ). Figure 6 shows the day when the maximum freezing value of the embankment model was reached and Fig. 7 shows the day of reaching the maximum freezing value in the cut model.

The reached freezing depths on other days that were found significant in the analysis of the winter period 2004/2005 are clearly shown in Table 2.

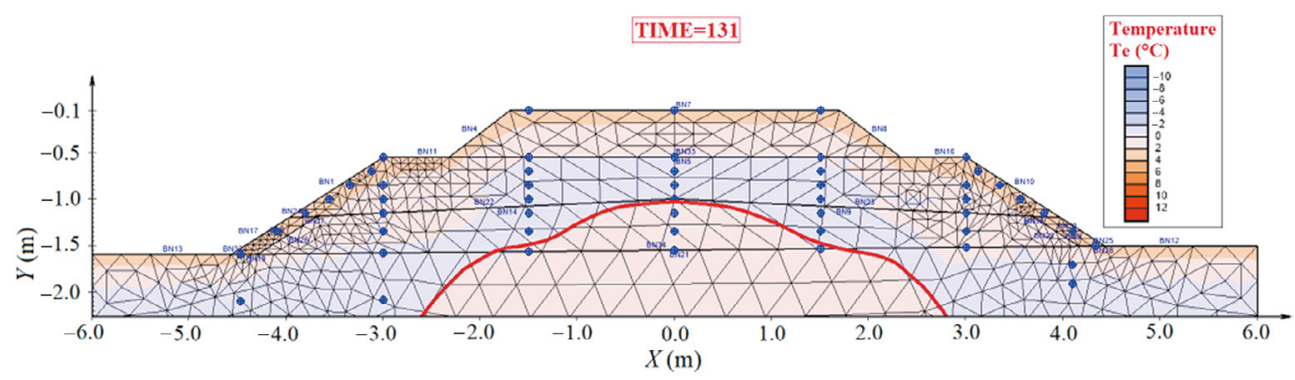

Figure 6: Reaching the maximum freezing depth in the model of embankment $-D_{F}=0.97 \mathrm{~m}$ (day $131, I_{F}=-448^{\circ} \mathrm{C} \cdot$ day).

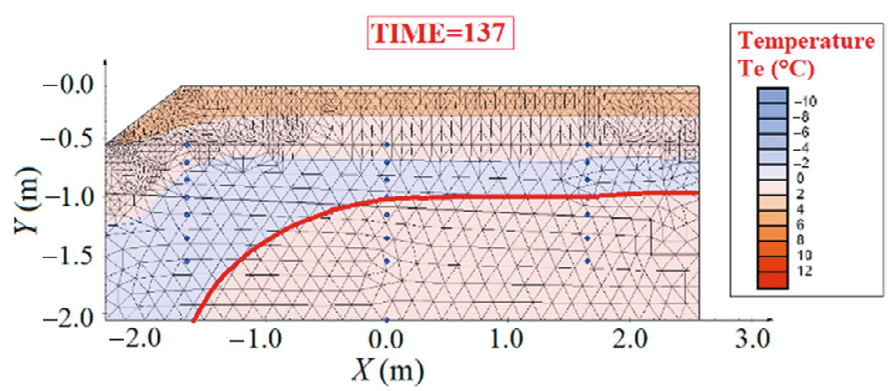

Figure 7: Reaching maximum freezing depth in the model of cut $-D_{F}=0.97 \mathrm{~m}$ (day 137 , $I_{F}=-422^{\circ} \mathrm{C} \cdot$ day $)$. 
Table 2: Overview of reached freezing depths of subgrade structure of the experimental stand DRETM.

\begin{tabular}{llclll}
\hline Model & Date & $\begin{array}{l}\text { Day } \\
\text { in a } \\
\text { model }\end{array}$ & $\begin{array}{l}\text { Average daily } \\
\text { air temperature } \\
\theta_{s}\left({ }^{\circ} \mathrm{C}\right)\end{array}$ & $\begin{array}{l}\text { Air frost } \\
\text { index } \\
I_{F}\left({ }^{\circ} \mathrm{C} \cdot \text { day }\right)\end{array}$ & $\begin{array}{l}\text { Depth of } \\
\text { freezing } \\
D_{F}(\mathrm{~m})\end{array}$ \\
\hline \multirow{2}{*}{ Embankment } & 9 February 2005 & 88 & $-17.3^{*}$ & -291 & 0.67 \\
& 14 March 2005 & 121 & -1.4 & $-464^{*}$ & 0.92 \\
& 24 March 2005 & 131 & 3.3 & -448 & $0.97^{*}$ \\
Cut & 9 February 2005 & 88 & $-17.3^{*}$ & -291 & 0.63 \\
& 14 March 2005 & 121 & -1.4 & $-464^{*}$ & 0.90 \\
& 30 March 2005 & 137 & 1.7 & -422 & $0.97^{*}$ \\
\hline
\end{tabular}

*Maximum value.

\section{CONCLUSION}

The numerical modelling of railway track (subgrade structure) freezing is a demanding process as the achieved results are affected by many parameters. The input data applied in this article was obtained by long-term experimental research, implemented at the experimental stands DRETM, and in cooperation with the Slovak Hydrometeorological Institute (provision of climatic characteristics for the town of Poprad).

The aim of this article was to assess the correctness of the design methodology of subgrade structure dimensioning with respect to the design of the protective layer thickness [2] and also to assess the possible impact of the method of rail track routing (embankment and cut) on the procedure of subgrade structure dimensioning for non-traffic load. The numerical modelling of subgrade structure freezing and the comparison of results was carried out on railway track models that characterize the real experimental stand DRETM, at the scale 1:1 (second measuring profile - embankment, third measuring profile - cut).

The results in Table 2 clearly indicate that the zero isotherm penetrated into the depth of $D_{F}=0.97 \mathrm{~m}$, which is $0.02 \mathrm{~m}$ below the subgrade surface level, in both types of rail track routing (embankment, cut). The applied value of the air frost index for the winter period $2004 / 2005\left(I_{F}=-464^{\circ} \mathrm{C} \cdot\right.$ day $)$ is approximately identical to the design frost index. The thickness of the protective layer of the experimental stand DRETM $\left(I_{F d}=-470^{\circ} \mathrm{C} \cdot\right.$ day $)$ was determined on the basis of this frost index. This value can thus be considered relevant and the design value of the protective crushed aggregate layer thickness, fr. 0/31.5 mm $(0.45 \mathrm{~m})$, is sufficient in the case of the applied course of the winter period. This is also confirmed by the course of the recorded winter period 2016/2017 in the measuring profile no. 2 (embankment) and no. 3 (cut) of the experimental stand DRETM, when by the frost index $I_{F}=-284^{\circ} \mathrm{C} \cdot$ day, both measuring profiles showed approximately the same depth of subgrade structure freezing (embankment $D_{F}=0.65 \mathrm{~m}$ and cut $D_{F}=0.63 \mathrm{~m}$ ).

It is interesting to notice that the maximum depth of subgrade structure freezing of the embankment model occurred 10 days after (and of the cut model 16 days after), reaching the maximum air frost index. This phenomenon may be based on the fact that in the cut subgrade structure the temperature during winter period is higher (frost acts on the top) than in the embankment (frost acts on the top and on the sides). This fact needs to be verified in the real stand (experimental stand DRETM, measuring profiles no. 1, 2 or 3, 4, 5 and 6) after several winter periods. 
Based on the above-mentioned results of experimental measurements and numerical modelling, we can state that it is necessary to update or adjust the design dimensioning methodology of subgrade structure, specified in Ref. [2]. It should also be supplemented with other design parameters, e.g. average annual temperature, as stated e.g. in our article in the proceedings [6].

\section{ACKNOWLEDGEMENT}

The presented results are the results of solving the VEGA grant project 1/0275/16 Optimization design of sleeper subgrade due to non-traffic load aspect.

\section{REFERENCES}

[1] SVHEAT, 2D/3D Geothermal Modelling, SVOFFICE 2009 - Geotechnical Modelling Suite, SoilVision Systems Ltd.: Saskatoon, Saskatchenwan, Canada, available at http://www.soilvision.com, 2018.

[2] TNŽ 73 6312, Design of Structural Layers of Subgrade Structures, GR ŽSR: Slovakia, 2005.

[3] Ižvolt, L., Railway Substructure - Stress, Diagnostics, Design, and Implementation of Body Construction Layers of Railway Subgrade, Scientific Monograph, University of Žilina: Žilina, 324 p., 2008 (in Slovak).

[4] Dobeš, P., Optimization the design of subgrade structure to the non-traffic load, Dissertation thesis, Faculty of Civil Engineering, University of Žilina, 136 p., 2015

[5] Pieš, J., Experimental analysis of the impact of not-transport load on the constructional thickness of protective layer of the subgrade, Diploma thesis, Faculty of Civil Engineering, University of Žilina, 89 p., 2017.

[6] Ižvolt, L., Dobeš, P. \& Pieš, J., Contribution to the modification of input data of subgrade structure dimensioning for non-traffic load according to the ŽSR methodology. Proceeding COMPRAIL, Lisbon, 1-3 July, 2018. 